Corrigendum

\title{
Corrigendum to “(-)-Epicatechin Prevents Blood Pressure Increase and Reduces Locomotor Hyperactivity in Young Spontaneously Hypertensive Rats"
}

\author{
M. Kluknavsky, ${ }^{1}$ P. Balis, ${ }^{1}$ A. Puzserova, ${ }^{1}$ J. Radosinska, ${ }^{2,3}$ A. Berenyiova, ${ }^{1}$ M. Drobna, ${ }^{1}$ \\ S. Lukac, ${ }^{4}$ J. Muchova, ${ }^{5}$ and I. Bernatova ${ }^{1}$ \\ ${ }^{1}$ Institute of Normal and Pathological Physiology, Centre of Excellence for Examination of Regulatory Role of Nitric Oxide in \\ Civilization Diseases, Slovak Academy of Sciences, Bratislava, Slovakia \\ ${ }^{2}$ Institute of Physiology, Faculty of Medicine, Comenius University, Bratislava, Slovakia \\ ${ }^{3}$ Institute for Heart Research, Slovak Academy of Sciences, Bratislava, Slovakia \\ ${ }^{4}$ Institute of Medical Physics, Biophysics, Informatics and Telemedicine, Faculty of Medicine, Comenius University, \\ Bratislava, Slovakia \\ ${ }^{5}$ Institute of Medical Chemistry, Biochemistry and Clinical Biochemistry, Faculty of Medicine, Comenius University, \\ Bratislava, Slovakia \\ Correspondence should be addressed to I. Bernatova; iveta.bernatova@savba.sk
}

Received 5 April 2017; Accepted 10 April 2017; Published 16 May 2017

Copyright ( $) 2017$ M. Kluknavsky et al. This is an open access article distributed under the Creative Commons Attribution License, which permits unrestricted use, distribution, and reproduction in any medium, provided the original work is properly cited.

In the article titled “(-)-Epicatechin Prevents Blood Pressure Increase and Reduces Locomotor Hyperactivity in Young Spontaneously Hypertensive Rats" [1], there was an error in the section "2.1. Animals and Treatment," where the sentence "Concentrated Epi solution $(100 \mathrm{mg} / \mathrm{mL})$ was prepared fresh every day before administration to rats by dilution of Epi in tap water $\left(85^{\circ} \mathrm{C}, 3 \mathrm{~min}\right.$, in water bath)" should be corrected to "Concentrated Epi solution $(10 \mathrm{mg} / \mathrm{mL})$ was prepared fresh every day before administration to rats by dilution of Epi in tap water $\left(85^{\circ} \mathrm{C}, 3 \mathrm{~min}\right.$, in water bath)."

\section{Reference}

[1] M. Kluknavsky, P. Balis, A. Puzserova et al., “(-)-Epicatechin Prevents Blood Pressure Increase and Reduces Locomotor Hyperactivity in Young Spontaneously Hypertensive Rats," Oxidative Medicine and Cellular Longevity, vol. 2016, Article ID 6949020, p. 14, 2016. 


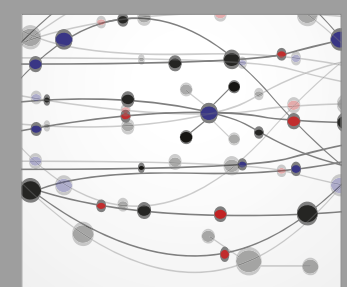

The Scientific World Journal
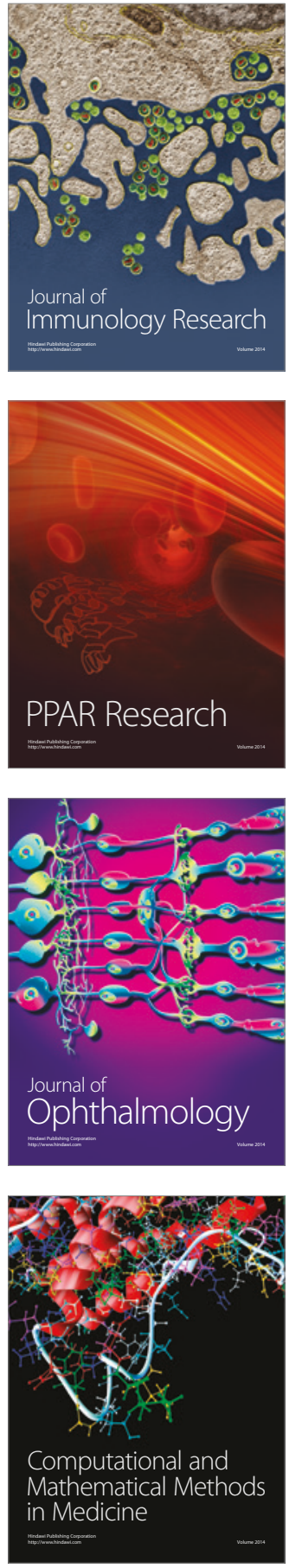

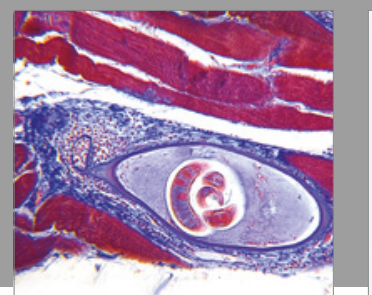

Gastroenterology Research and Practice
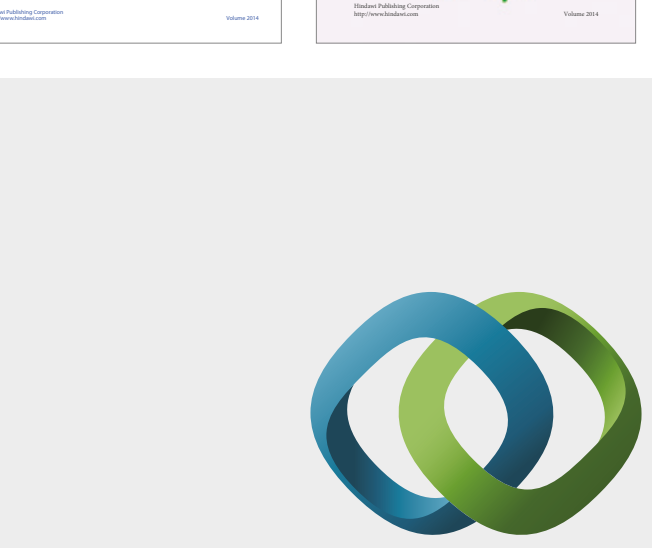

\section{Hindawi}

Submit your manuscripts at

https://www.hindawi.com
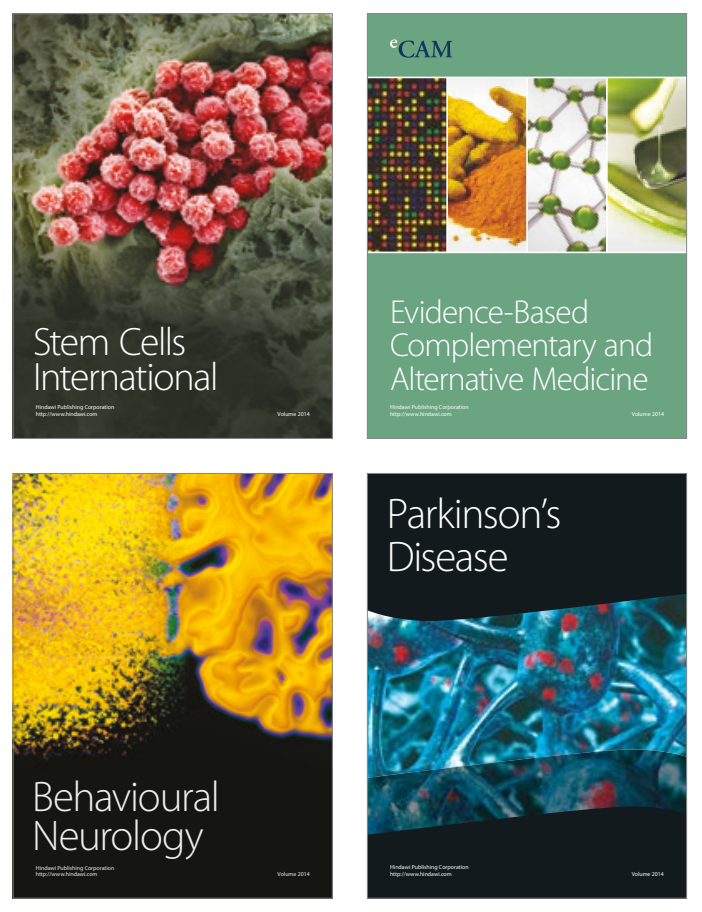
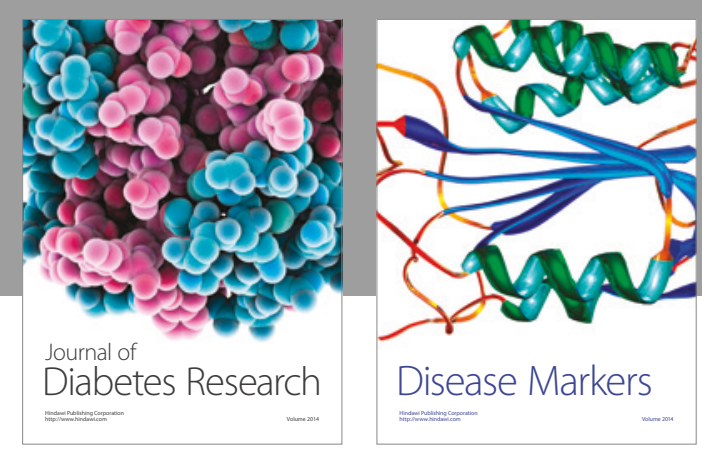

Disease Markers
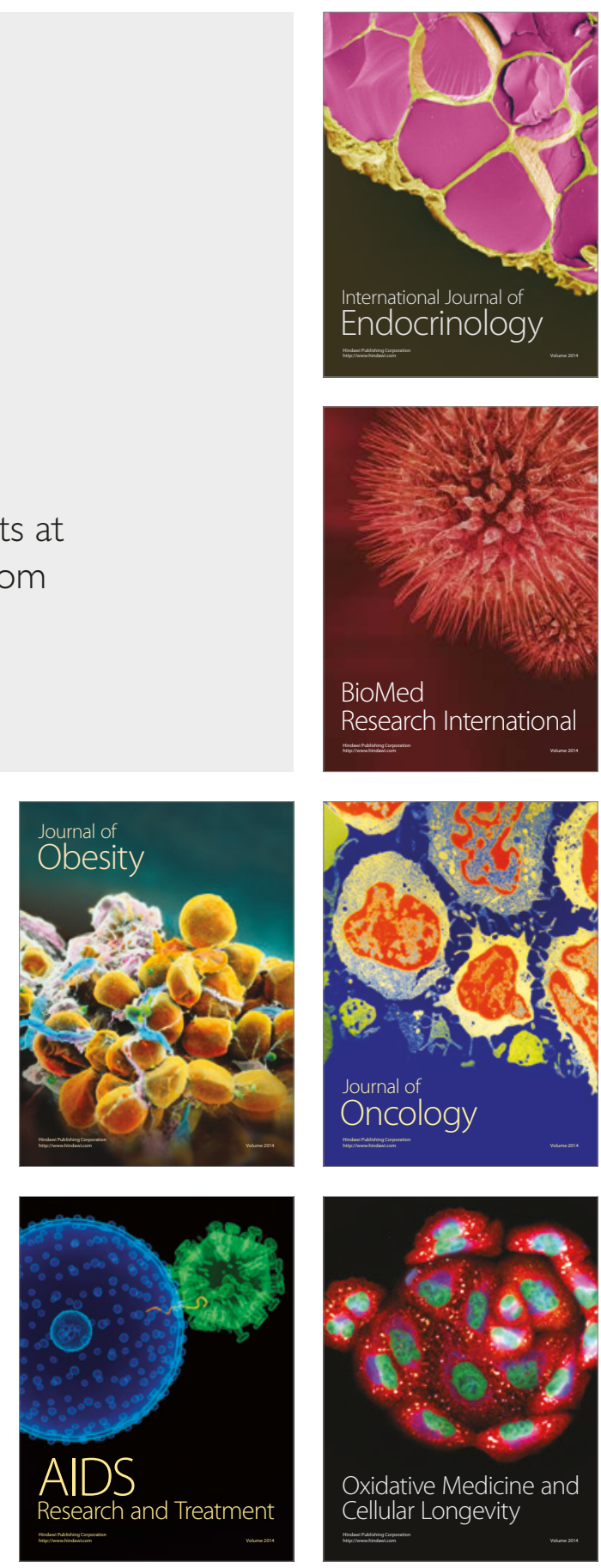